Hegemonia - Revista Eletrônica do Centro Universitário Euro-Americano

ISSN: 1809-1261

UNIEURO, Brasília, número 30, Julho-Dezembro de 2020, pp. 2-27.

\title{
O CUIDADOR DO IDOSO NO CONTEXTO FAMILIAR
}

\section{CAREGIVING FOR THE ELDERLY IN THE FAMILY CONTEXT}

\author{
Luci Lemos Barbosa Borges ${ }^{1}$ \\ Iolanda Bezerra dos Santos Brandão ${ }^{2}$ \\ Lídia de Oliveira Xavier ${ }^{3}$ \\ Elza de Paula Souto Faria da Costa ${ }^{4}$
}

\section{RESUMO}

O número de idosos cuidadores está crescendo e a responsabilidade de cuidar de um idoso dependente normalmente recai sobre um familiar também idoso; o cônjuge é a primeira alternativa, seguida pela filha e/ou filho. O objetivo geral deste estudo é investigar as dificuldades do idoso no exercício do papel de cuidador de outro idoso no contexto familiar. Trata-se de um estudo de abordagem qualitativa, exploratória. Os seis participantes da investigação são cuidadores familiares idosos residentes em Brasília. Para a coleta de dados, utilizou-se entrevista semiestruturada e as informações obtidas dos cuidadores foram gravadas e, após, transcritas, para serem interpretadas por meio de Análise de Conteúdo. Dentre os resultados, verificou-se que os idosos cuidadores entrevistados eram na maioria do gênero feminino: cinco mulheres e um homem. Quanto ao grau de parentesco entre idoso cuidador e idoso cuidado entrevistou-se um marido, duas esposas e três filhas. As principais queixas de doenças dos idosos cuidadores foram: depressão, estresse e insônia. Concluiu-se que as dificuldades enfrentadas pelos idosos cuidadores estão na necessidade de ajuda de uma pessoa treinada, na falta de informações sobre a doença do idoso dependente, na ausência de outros familiares para dividir as responsabilidades com o cuidado e ter um tempo para o lazer, sentir o reconhecimento de seu trabalho de cuidador pelas outras pessoas da família, ou seja, receber mais apoio, tanto formal, das instituições, quanto informal, da família, amigos e vizinhos.

Palavras-chave: Idoso. Cuidador familiar. Saúde do idoso.

\footnotetext{
${ }^{1}$ Faculdade Laboro. Portugal. E-mail: lucyborges7@gmail.com

${ }^{2}$ Faculdade Laboro. Portugal. E-mail: iolandabsb@gmail.com

${ }^{3}$ Centro Universitário Euro-Americano. Brasil. E-mail: lidia.xavier@unieuro.edu.br

${ }^{4}$ Faculdade de Filosofia, Ciências e Letras da Fundação Educacional de São Gabriel. Brasil. E-mail: elza_souto@hotmail.com
} 
Hegemonia - Revista Eletrônica do Centro Universitário Euro-Americano

ISSN: 1809-1261

UNIEURO, Brasília, número 30, Julho-Dezembro de 2020, pp. 2-27.

\begin{abstract}
The number of older caregivers is growing and the responsibility for caring for a dependent elderly person usually rests with an elderly relative; the spouse is the first alternative to being the husband's caregiver. The general objective of this study was to investigate the difficulties of the elderly in the role of caregiver of another elderly in the family context. This is a qualitative, exploratory study. The six research participants are elderly family caregiver living in Brasilia. For data collection, we used a semi-estructured interview and the information obtained from caregiver was recorded and later transcribed to be interpreted by Content Analysis. Among the results, it was found that were mostly female: five women and one man. Regarding the relationship between elderly caregiver, one husband, two wives and three daughters were interviewed. The main complaints of disease of the elderly caregiver were depression, stress and insomnia. It was concluded that difficulties faced by the elderly caregiver are in need of help from a trained person, in the lack of information about the dependent elderly's disease, in the absence of other family members, to share the responsibilities with the care and to take to take time to leisure, feel the recognition of their caregiver work by other family members, that is, receive more support, both formally, from institutions, and informally, from family, friends and neighbors.
\end{abstract}

Keywords: Old man. Family caregiver. Health of the elderly.

\title{
INTRODUÇÃO
}

O envelhecimento populacional é um fato real que deve ser entendido como uma grande conquista da humanidade e não como um problema. É um fenômeno recente que vem ocorrendo em ritmos diferentes, por isso as famílias ainda estão se adaptando a esse novo desafio.

A velhice não é uma doença. Grande parte das pessoas de idade avançada tem boa saúde, o que lhes permite viver de forma autônoma e feliz. Mas, o processo do envelhecer acarreta perdas funcionais, emergindo alterações vitais. As pessoas convivem com a presença de possíveis complicações, perdendo a independência funcional e evoluindo para a necessidade de cuidados de longa duração. As alterações físicas e emocionais podem comprometer, em diferentes graus, a percepção de bem-estar e qualidade de vida dos idosos e aumentam a possibilidade de um familiar idoso precisar tornar-se um cuidador, denominado cuidador informal, sem remuneração e sem folga (ABDALA, KIMURA, DUARTE, LEBRÃO \& SANTOS, 2015). 
Hegemonia - Revista Eletrônica do Centro Universitário Euro-Americano

ISSN: 1809-1261

UNIEURO, Brasília, número 30, Julho-Dezembro de 2020, pp. 2-27.

$\mathrm{O}$ ato de cuidar pode ser executado por um familiar, por profissionais ou por instituições de saúde. No entanto, faz parte da cultura brasileira a permanência do idoso em sua casa. A convenção sociocultural preconiza que cabe ao cônjuge zelar pelo cuidado do parceiro como uma questão de solidariedade, respeito e responsabilidade (PEREIRA \& DIAS, 2007).

Nas famílias menos abastadas, o cuidador do idoso quase sempre mora na mesma casa: a esposa ou uma filha; já nas famílias com situação financeira melhor, pode haver a presença de um cuidador formal. Existem as Instituições de Longa Permanência para Idosos, porém estão sempre superlotadas, com falta de recursos materiais e humanos.

Segundo o art. $3^{\circ}$ do Estatuto do Idoso (BRASIL, 2011) é obrigação da família acolher o idoso com paciência, amor e carinho, fazendo com que se sinta útil e amado. Porém, cuidar do idoso no âmbito familiar constitui um desafio para o outro cônjuge, visto que esse também, provavelmente, será idoso com as fragilidades próprias da idade.

A diminuição da capacidade de cuidar de si e a exigência de uma reestruturação da família para lidar com o cuidado traz inseguranças ao cuidador e à família. É para conhecer essa dinâmica das famílias onde um idoso com 60 anos ou mais cuida de outro idoso e doente também com 60 anos ou mais, que este trabalho investiga a figura do cuidador familiar através de entrevistas com seis cuidadores de outros idosos.

Quando se discute o processo do cuidador do idoso, muitas interrogações ainda necessitam de respostas, tornando indispensáveis leituras e pesquisas que deem conta de toda a complexidade que este tema apresenta. Isto por si só justifica a relevância social e educacional dessa pesquisa, na medida em que se torna mais uma fonte de investigação sobre o lidar no cotidiano do idoso. A pesquisa traz uma resposta para o problema: Quais as dificuldades encontradas pelo idoso cuidador nos cuidados dispensados a outro idoso?

Ao investigar o processo do cuidar do idoso, pretende-se chamar a atenção para a pessoa do cuidador e para a real necessidade de uma capacitação, tanto no aspecto físico da doença do idoso, como uma preparação psicológica para ser cuidador familiar. $\mathrm{O}$ intuito é apresentar subsídios para se pensar na formação e no apoio emocional dos cuidadores, abrindo espaço para futuras ações no campo das políticas públicas de saúde. 
Hegemonia - Revista Eletrônica do Centro Universitário Euro-Americano

ISSN: 1809-1261

UNIEURO, Brasília, número 30, Julho-Dezembro de 2020, pp. 2-27.

O objetivo geral desta pesquisa foi investigar as dificuldades do idoso no exercício do papel de cuidador de outro idoso no contexto familiar. Os objetivos específicos foram: conhecer os padrões de funcionamento das famílias nos cuidados com idosos dependentes no domicílio; traçar o perfil do idoso que se torna um cuidador familiar de outro idoso e; entender as consequências da sobrecarga de trabalho do cuidador idoso para sua saúde e vida pessoal.

\section{METODOLOGIA}

O estudo é uma pesquisa de abordagem qualitativa de natureza exploratória. Foi escolhida por possibilitar a busca de experiências de vida dos participantes, pessoas idosas que, no contexto familiar, são responsáveis pelos cuidados de outro idoso.

Foram 6 o número de participantes da investigação, cuidadores familiares idosos ${ }^{5}$ residentes em Brasília que, voluntariamente, aceitaram ser entrevistados em seus domicílios, ou outro local por eles escolhidos de maneira que não atrapalhasse sua rotina de cuidador.

O instrumento de coleta dos dados foi uma entrevista semiestruturada, ferramenta relevante por propiciar o acesso direto a pessoas que relatam como compreendem e como vivem um determinado problema social (GASKELL \& BAUER, 2011). Além disso, a velhice é individual: cada um tem sua saúde, suas experiências. Por isso a decisão de usar entrevistas individuais.

Para garantir a eficácia das entrevistas foram observadas, conforme sugestão de GASKELL \& BAUER (2011, p. 1) a seleção criteriosa dos entrevistados; 2) o emprego de pseudônimos, um nome de flor que lhes deu personalidade sem identificá-los e os apresenta como pessoas especiais; 3) perguntas abertas, evitando respostas de "sim" ou "não"; 4) utilização de um "tópico guia" para assegurar que os temas centrais fossem abordados.

\footnotetext{
${ }^{5}$ De acordo com o Estatuto do Idoso, Lei 10.741/2003, idosos são as pessoas com 60 anos ou mais (Brasil, 2011).
} 
Hegemonia - Revista Eletrônica do Centro Universitário Euro-Americano

ISSN: 1809-1261

UNIEURO, Brasília, número 30, Julho-Dezembro de 2020, pp. 2-27.

Todas as entrevistas foram precedidas de conversa informal onde a entrevistadora solicitou aos cuidadores a assinatura no Termo de Consentimento Livre e Esclarecido. Em cumprimento à Resolução CNS 466/12, do Ministério da Saúde, o projeto de pesquisa foi submetido à apreciação do Comitê de Ética em Pesquisa (CEP), responsável pelos aspectos éticos das investigações com seres humanos, que deu Parecer favorável sob o n ${ }^{\circ} 162 / 2018$.

As informações obtidas dos cuidadores, depois de gravadas, foram transcritas e analisadas através de Análise de Conteúdo conforme Bardin (2011).

Nós tópicos seguintes este trabalho se põe a apresentar as discussões, conceituações e interpretações teóricas concernentes ao tema escolhido.

\section{PROCESSO DE ENVELHECIMENTO}

A Organização Mundial da Saúde (OMS) definiu que idoso é o indivíduo com 60 (sessenta) anos ou mais em países em desenvolvimento como o Brasil e 65 anos ou mais em países desenvolvidos. No entanto, não é possível compreender a velhice considerando apenas o número de anos que a pessoa viveu. Além da idade cronológica, considera-se também a idade biológica, de difícil definição, pois não existe um marcador biológico claro que defina o envelhecimento. Considera-se também a idade psicológica que se refere à capacidade de percepção, aprendizagem e memória; e a idade social, referente ao desempenho de papéis socialmente determinados para cada idade cronológica (FONTAINE, 2010).

A noção de envelhecimento vem se transformando com o passar dos anos de acordo com cada cultura. De acordo com Rozendo e Justo

$\mathrm{Na}$ atualidade é comum nos defrontarmos com diferentes nomes para designar as idades avançadas da vida: futuridade, senilidade, maturidade, melhor idade, nova juventude, quarta idade e assim por diante. Duas delas apresentam significados matriciais que delimitam formas de existência distintas, a ‘velhice' e a ‘terceira idade' (ROZENDO \& JUSTO, 2011, p. 144).

Envelhecimento é o processo inerente ao ser humano, não é um momento da vida, começa no nascimento, evolui, é um ato contínuo; velhice é o estado de ser velho, 
Hegemonia - Revista Eletrônica do Centro Universitário Euro-Americano

ISSN: 1809-1261

UNIEURO, Brasília, número 30, Julho-Dezembro de 2020, pp. 2-27.

estado da pessoa com idade avançada que sofreu o processo de envelhecer. É irreversível, apesar do avanço da medicina (PESSOA, 2008).

A velhice é percebida de modo diferente por cada idoso e suas características diferem ao longo dos anos sem estarem ligadas à idade cronológica. A velhice, portanto, é um fenômeno dinâmico. É preciso entender o processo de envelhecimento, não como um avanço da idade cronológica, pois, neste processo, estão envolvidos os fatores biológicos, sociais, culturais e históricos (BEAUVOIR, 1990).

Também é importante considerar o gênero ao estudar o envelhecimento. Há uma tendência de considerar as variações no processo do envelhecer pautadas nas identidades feminina e masculina (BEAUVOIR, 1990). A longevidade é maior na população feminina, fenômeno conhecido como "feminização". Os fatores biológicos, as diferenças de gênero expressas no comportamento interferem na mortalidade (CAMARANO, 2004).

A preocupação científica com o idoso e com o processo de envelhecimento humano é recente. Iniciou em 1909 com a criação da especialidade chamada Geriatria, que estuda as questões orgânicas relativas à área médica. Nessa época, o envelhecimento era entendido como um processo de degeneração celular. Segundo Neri (2009), o envelhecimento era pouco estudado porque se entendia que o indivíduo nasce, cresce, encontra a estabilidade na vida adulta e declina na velhice, obedecendo a um modelo biomédico. A disciplina científica que estuda os idosos, suas características e o processo do envelhecimento nos aspectos biopsicossociais é a Gerontologia, que aborda aspectos não orgânicos.

É importante distinguir envelhecimento primário ou senescência de envelhecimento secundário ou senilidade. $\mathrm{O}$ primeiro refere-se às mudanças próprias do envelhecer: alterações de memória, perdas sensório-perceptivas (audição, visão, percepção e tempo de reação), redução da vitalidade (reduz a capacidade pulmonar, a força muscular e o metabolismo), maior aparecimento de doenças, mudanças na aparência, o que implica um problema social: o medo de parecer velho (BALTHES \& SMITH, 2006). Esse último fator é muito lembrado pela indústria cosmética, que incentiva a busca pelo retardamento dos sinais físicos do envelhecimento, já que atualmente a sociedade ocidental cultua a aparência jovem e bela. $\mathrm{O}$ envelhecimento 
Hegemonia - Revista Eletrônica do Centro Universitário Euro-Americano

ISSN: 1809-1261

UNIEURO, Brasília, número 30, Julho-Dezembro de 2020, pp. 2-27.

secundário é a união das transformações do envelhecimento primário aos hábitos saudáveis, ao otimismo, ao apoio social e à condição financeira. Assim, percebe-se que o aumento de doenças na velhice também é consequência de maus hábitos adquiridos ao longo da vida, por exemplo, tabagismo, consumo de álcool, ausência de atividade física, entre outros, caracterizando o envelhecimento como patológico (BALTHES \& SMITH, 2006).

\subsection{Saúde na velhice}

É normal um declínio cognitivo a partir da meia-idade, no entanto, é mais comum que ocorra após os 70 anos. A memória também é afetada, diminui a capacidade de reter informações recentes (memória episódica) (BALTHES \& SMITH, 2006). A fragilidade é progressiva, mas pode-se preveni-la e tratar os sintomas (NERI, 2009).

Quando o idoso possui uma incapacidade física, o ambiente físico e social deve estimulá-lo. Se a perda da autonomia é vista como um evento negativo, o desejo de manter-se produtivo continua ao longo do envelhecimento. A percepção do idoso de que ele ainda pode ser útil está associada ao melhor funcionamento físico e maior longevidade (NERI, 2009).

É preciso diferenciar independência de autonomia. A primeira refere-se à capacidade que a pessoa tem de ser ativa sem precisar de ajuda, tem relação direta com a habilidade física; a segunda é a capacidade de tomar decisões sobre sua vida, tem relação direta com a capacidade mental. Assim, é possível que o idoso tenha autonomia sem ser independente e vice-versa, por exemplo, pode estar em uma cadeira de rodas (dependente), mas ter sua autonomia preservada (decide sobre sua vida) (THOMAS, 2011).

As relações sociais são benéficas para todos, especialmente para idosos. Aqueles que se envolvem em atividades sociais têm mais motivação para cuidar da própria saúde, mas a participação social difere com relação ao gênero. $O$ engajamento social das mulheres idosas é um fator protetor de limitações físicas e cognitivas; em compensação, as limitações da saúde nos homens podem ser prejudiciais para que se disponham a ter 
Hegemonia - Revista Eletrônica do Centro Universitário Euro-Americano

ISSN: 1809-1261

UNIEURO, Brasília, número 30, Julho-Dezembro de 2020, pp. 2-27.

compromissos sociais (THOMAS, 2011). As mulheres participam mais de atividades ocupacionais e os homens, de atividades físicas. Essa sociabilidade também tem relação com a escolaridade, com a situação financeira, com o estado de saúde. No entanto, ser ativo, para o idoso, não significa ter o ritmo de vida de quando era jovem, pois as limitações e as diferenças individuais existem e precisam ser respeitadas (BEAUVOIR, 1990).

Porém, mesmo com doenças e fragilidades, é possível que os idosos se sintam felizes e confortáveis com a vida que levam. O grande desafio das políticas públicas e da sociedade atual é dar condições para uma velhice saudável. Essas ações reduziriam os custos no serviço de saúde e eles deixariam de ser tratados como onerosos à sociedade. Para isso, não se deve focar só no idoso, mas também nas famílias e nos profissionais da saúde (RIBEIRO, NERI, CUPERTINO \& YASSUDA, 2009).

Muitos idosos acreditam que apenas os medicamentos irão solucionar seus problemas de saúde e os utilizam como "apoio químico" para controlá-los, ou seja, não buscam ou não encontram estímulos para lidar com as dificuldades que aparecem. Também ocorre por parte do idoso uma rejeição ao próprio corpo envelhecido, fazendo com que busquem fármacos, ditos milagrosos, para evitar as marcas físicas do envelhecimento (RIBEIRO, NERI, CUPERTINO \& YASSUDA, 2009). Nesse sentido, o psicólogo pode auxiliar desenvolvendo ações para que o idoso aprenda a lidar com a sua condição, a evitar o envelhecimento patológico e incentivar sua participação na comunidade. No entanto, nenhuma dessas metas será atingida se não houver auxílio de equipe multidisciplinar, de vários outros profissionais, pois o objetivo é promover a saúde global do idoso (OTTONI, 2011).

Saúde é um projeto pessoal que requer cuidados preventivos do corpo e no comportamento, pois não é a ausência de qualquer doença, mas é o idoso ter habilidade para lidar com as perdas e manter a autonomia (OTTONI, 2011). Nesse sentido ao depararmos com o processo do envelhecimento como parte constitutiva dos seres vivos e, em especial dos seres humanos, a perspectiva é a construção do entendimento desse processo e, assim do estabelecimento de projetos de vida que viabilizem o bom 
Hegemonia - Revista Eletrônica do Centro Universitário Euro-Americano

ISSN: 1809-1261

UNIEURO, Brasília, número 30, Julho-Dezembro de 2020, pp. 2-27.

envelhecer sejam através de ações diretas da pessoa e dos seus familiares, sejam por intermédio das ações das políticas públicas e da comunidade de um modo geral.

1.2 A velhice no contexto brasileiro

Entre 1950 e 2000, a expectativa de vida, no mundo, aumentou dezenove vezes e o número de pessoas com cem anos ou mais deverá aumentar quinze vezes até o ano de 2050 (BARROS, 2013) ${ }^{6}$. No Brasil, a taxa de fecundidade passou de 6,2 filhos por família nos anos 1960 para 1,77 em 2013, mostrando um cenário com mais idosos e menos crianças (FIOCRUZ, 2014). Devido a essa transformação, o país tem se deparado, em pouco tempo, com o aumento de enfermidades crônicas que exigem cuidados e tratamentos complexos e constantes. Nas próximas décadas, é prevista uma população com maior número de idosos mais velhos, mais internações hospitalares e famílias com menos disponibilidade para o cuidado.

A atenção ao idoso, no Brasil, é organizada em três níveis conforme determina a OMS: no nível primário, as condições de saúde do idoso são monitoradas e trabalha-se com a prevenção das doenças através de vacinação e programas de hábitos saudáveis. Essa assistência primária é prestada nos Postos de Saúde. Os profissionais se organizam para prestar assistência domiciliar, geralmente pertencentes ao Programa Saúde da Família, Agentes Comunitários de Saúde e clínicos gerais. Para os idosos mais graves que têm a mobilidade comprometida, há programas de internação domiciliar. A responsabilidade pelo gerenciamento dos Postos de Saúde pertence aos municípios, ou seja, às Prefeituras Municipais (BRASIL, 2016).

Se o idoso precisar de atendimento especializado, é encaminhado para a atenção secundária para consultas ambulatoriais nas Unidades de Pronto Atendimento (UPAs), hospital-dia, serviço domiciliar e reabilitação. A assistência prestada é de média complexidade. Conta com leitos de observação e médicos especialistas na área de Pediatria, Ginecologia, Cardiologia, Oftalmologia, Endocrinologia, Ortopedia,

\footnotetext{
${ }^{6}$ Essa informação foi elaborada a partir de dados disponibilizados antes do advento da pandêmica causada pelo COVID-19; atualmente novas projeções estão sendo elaboradas e devem contrariá-la.
} 
Hegemonia - Revista Eletrônica do Centro Universitário Euro-Americano

ISSN: 1809-1261

UNIEURO, Brasília, número 30, Julho-Dezembro de 2020, pp. 2-27.

Psiquiatria, Enfermagem e Odontologia. Fazem parte dessa assistência os serviços de urgência e emergência a cargo também do Serviço de Atendimento Móvel à Urgência (SAMU). Quando o estado clínico estabilizar, o paciente retorna para o acompanhamento na atenção primária (BRASIL, 2016).

A atenção terciária possui hospitais de grande porte, recursos físicos, humanos e tecnológicos mais específicos, atende os pacientes cuja condição de saúde exige tratamento de alto custo, cirurgia eletiva e reabilitação mais complexa para cuidar de vidas em risco como ao receber a quimioterapia e/ou a radioterapia. Os três níveis precisam estar integrados para uma boa atuação, o que depende essencialmente de uma boa gestão (BRASIL, 2016).

Essa descentralização promove um melhor atendimento à população idosa, pois cada unidade presta determinada assistência, há uma troca de informações controlada por um banco de dados ou protocolos com registros eletrônicos das informações médicas dos três níveis. Em locais onde não há serviços de saúde públicos, a União contrata serviços de hospitais particulares.

Existe também a assistência farmacêutica aos idosos. A medicação para hipertensão e diabetes é distribuída gratuitamente, tal como os medicamentos de alto custo para tratamento de doenças específicas São disponibilizadas vacinas para atender à população idosa prioritariamente (BRASIL, 2016).

Devido aos avanços tecnológicos da medicina, algumas doenças que antes eram letais, hoje são curadas ou têm os sintomas controlados. Assim, atualmente, as pessoas têm um prolongamento da vida convivendo com doenças. Contudo, os idosos apresentam menos incapacidades físicas se comparados a idosos do século XX na mesma faixa etária (BALTHES \& SMITH, 2006).

Considerando essas mudanças, o foco das intervenções com idosos está visando à qualidade de vida. Porém, não se percebe essa qualidade na vida de todos os idosos. Eles se deparam com estressores específicos, diferentes dos jovens, o que exige deles uma reorganização em suas vidas. Essas transformações, se não forem bem conduzidas, podem comprometer a saúde do idoso. Assim a qualidade de vida na velhice tem 
Hegemonia - Revista Eletrônica do Centro Universitário Euro-Americano

ISSN: 1809-1261

UNIEURO, Brasília, número 30, Julho-Dezembro de 2020, pp. 2-27.

significados diferentes em cada região do país e em diferentes classes socioeconômicas (NERI, 2009).

Esta complexidade que envolve o processo de envelhecimento traz consigo mudanças no modo de vida do idoso, no autocuidado, na participação na sociedade, na forma como percebe a si mesmo e no lugar que ele ocupa na família. Este último aspecto é importante, pois vem aumentando em todo o mundo a figura do cuidador familiar, que tem função importante na manutenção da saúde do idoso (BORN, 2008). Essa percepção é essencial ao tratarmos do processo do envelhecimento e de todos os manejos necessários ao desenvolvimento de ações que fortaleçam a qualidade de vida dos idosos e, consequentemente dos seus familiares e dos que representam a figura do cuidado e da atenção a essas pessoas, ou seja, os cuidadores.

\section{PERFIL DOS CUIDADORES FAMILIARES DE IDOSOS}

A família vem evoluindo ao longo do tempo sob influências históricas e culturais. Dentro do sistema familiar, são definidos os papéis individuais e cumprimento de tarefas. Antigamente, o drama do casal era cuidar de tantos filhos, hoje as famílias enfrentam a angústia de assistir seus idosos, já que as maiores transformações na estrutura familiar vêm da inserção da mulher, rotulada como a cuidadora, no mercado de trabalho (RAVAGNI, 2008).

O Estado tenta fazer a sua parte, principalmente em relação ao aumento da informação quanto aos bons hábitos alimentares, o incentivo à prática de atividade física, a criação de leis de proteção aos idosos. A desigualdade social devido à má distribuição da renda é marcante: de um lado, pessoas em condições financeiras excelentes, o que influi nos cuidados com seus idosos facilitando a longevidade; de outro, uma população à beira da miséria, vivendo em condições precárias, dando lugar à velhice doente e precoce (BARROS, 2013).

É relevante salientar que o cuidador familiar é a alternativa predominante de cuidados ao idoso, mas nem sempre é possível. Há um contingente de idosos que não possui família, há os que a possuem muito pobre ou ainda todos os familiares precisam 
Hegemonia - Revista Eletrônica do Centro Universitário Euro-Americano

ISSN: 1809-1261

UNIEURO, Brasília, número 30, Julho-Dezembro de 2020, pp. 2-27.

trabalhar. Diante dessa polêmica, conclui-se que, embora a família seja a melhor alternativa, nem sempre conseguirá custear os gastos dessa função (MUNHOZ, RAVAGNI \& LEITE, 2008).

Cada idoso enfrenta seus problemas de saúde de maneira individual conforme Ravagni (2008), pois os fatores pessoais (idade, sexo, situação financeira) e externos (ambiente) influenciam na saúde, tornando-o capaz ou incapaz de cuidar de si mesmo. Em ruas esburacadas que provocam quedas, longas esperas no ponto de ônibus, casas precárias sem facilitadores como rampas, corrimão, barra de apoio no banheiro, elevador, podem acelerar as doenças próprias do envelhecimento. É neste cenário que surge a necessidade do cuidador familiar. Nas famílias mais pobres, há duas alternativas: internar em uma instituição o idoso que necessita de cuidados ou designar outro familiar idoso como cuidador. Para o restante da família que trabalha, esse papel é destinado para o outro idoso que mora sob o mesmo teto, deixado em segundo plano, visto muitas vezes como uma pessoa sem utilidade por não mais fazer parte da força de trabalho remunerado (MOREIRA \& NOGUEIRA, 2008).

O autor Born (2008) compreende situações diferentes dependendo do grau de parentesco: a esposa é a primeira alternativa para ser a cuidadora do marido, mas dificilmente ele é capaz de ser o cuidador da mulher. A atribuição de papéis e tarefas de cuidar seguem normas culturais que esperam do homem o sustento material da família e a autoridade; e, da mulher, a organização da vida familiar, o cuidado dos idosos e tudo o que se relacione a casa, inclusive essa é a realidade também presente para as mulheres que trabalham fora. Camargo (2010, p. 236) diz que: "A literatura internacional apresenta quatro fatores presentes na designação da pessoa que assume o cuidado ao idoso dependente: parentesco (cônjuges), gênero (principalmente mulher), proximidade física (vive junto), e proximidade afetiva (conjugal, pais e filha)".

$\mathrm{Na}$ ausência da esposa, a probabilidade é que o responsável seja a filha mais velha, o que pode trazer como recompensa a aproximação entre pais e filhos e um sentimento de retribuição pelos cuidados que os pais lhe destinaram ao longo da vida e repetindo o padrão cultural de que cuidar é atribuição de mulher (CAMARANO, 2004). Porém, estas não são as únicas razões que levam a mulher a cuidar do idoso da família. 
Hegemonia - Revista Eletrônica do Centro Universitário Euro-Americano

ISSN: 1809-1261

UNIEURO, Brasília, número 30, Julho-Dezembro de 2020, pp. 2-27.

Pode ser por manter o bem-estar do idoso com quem se identifica, pela gratidão que recebe dele, por sentimento de culpa do passado, para evitar a censura dos amigos (BORN, 2008).

Entre as tarefas habituais do cuidador familiar, segundo Born (2008), estão: cozinhar, lavar, acompanhar o idoso aos passeios, assistir o idoso na sua movimentação em casa, ajudar na higiene e cuidados pessoais, administrar o dinheiro e os medicamentos, tranquilizar o idoso nos momentos de crise, ajudá-lo na comunicação com os outros quando ele apresenta dificuldades, alcançar um copo d'água, acomodá-lo em frente à TV, ou seja, a vida do cuidador é só cuidar do idoso 24 horas por dia, ele mesmo não tem vida própria.

A quebra dos laços de solidariedade reduz a possibilidade de mais membros da família cuidarem, coletivamente, de um idoso dependente; e a matriarca idosa, então, enfrenta sozinha as várias dificuldades desse encargo. Para Gonçalves, Leite, Hildebrandt, Bisogno, Biasuz \& Falcade (2013), a qualidade de vida do idoso e de seu cuidador estão entrelaçadas e desenvolvem-se juntas, pois o cuidar de idosos expõe o cuidador a doenças. Na medida em que o cuidador é idoso também vai adquirindo incapacidades, apresenta cada vez mais dificuldades para cuidar de si mesmo e do outro, o que aumenta a vulnerabilidade de ambos. Por isso, casais idosos devem ser avaliados clinicamente como uma unidade.

As dificuldades enfrentadas pelo idoso que cuida de outro idoso, no contexto domiciliar, são inúmeras: perda do companheiro, perda da privacidade, ônus físico, psíquico e financeiro, desinformação sobre a doença, ausência de suporte emocional, conflitos familiares, não divisão das tarefas e sobrecarga de papéis. É comum ocorrer exclusão social, isolamento afetivo, depressão, transtornos do sono, agravados pelo fato de cuidador e paciente morarem na mesma casa (FRATEZI, GUTIERRES \& FALCÃO, 2010).

Estudo realizado por Neri (2009) descreveu características que dificultam a prestação de cuidados de um idoso a outro idoso: ônus físico, falta de preparo e de informação, competição entre papéis profissionais e familiares, a solidão e os conflitos dentro da família. 
Hegemonia - Revista Eletrônica do Centro Universitário Euro-Americano

ISSN: 1809-1261

UNIEURO, Brasília, número 30, Julho-Dezembro de 2020, pp. 2-27.

Na medida em que a doença vai se agravando, as dificuldades vão se tornando maiores e dificultando as breves ausências do cuidador, tão necessárias para sua interação com amigos e vizinhos (BORN, 2008).

\begin{abstract}
Em razão da interdependência entre os membros, à medida que uma pessoa idosa desenvolve uma enfermidade, ocorre uma mudança de papéis entre os familiares, que altera a estrutura e a dinâmica do grupo. [...] As alterações desencadeadas na dinâmica familiar acontecem, especialmente, em virtude da repetição de visitas ao serviço de saúde, do uso de medicamentos, de cuidados específicos, de recidivas e reinternações hospitalares ao longo do processo de adoecimento. Por vezes, a incapacidade para lidar com uma situação nova acaba afetando as relações entre irmãos, entre pais e filhos ou até mesmo entre cônjuges (FRATEZI, GUTIERREZ \& FALCÃO, 2010, p. 194).
\end{abstract}

Na pesquisa de Perracini \& Neri (2002) com cuidadores de idosos de alta dependência sobre as tarefas de cuidado, atividades semelhantes foram classificadas como fáceis e difíceis por diferentes cuidadoras. Para essas cuidadoras, o que elas mais necessitam é de ajuda de uma pessoa treinada e ter alguém da família com quem dividir as responsabilidades para ter um pouco de lazer. Mesmo que os cuidados sejam distribuídos entre os membros da família, a carga mais pesada é carregada por um só: o cuidador principal. A sobrecarga é maior no início do desempenho do trabalho de cuidador, depois diminui e estabiliza, dependendo de como as tarefas modificam sua vida.

\title{
2.1 Apoio social formal e informal ao cuidador
}

Apoio social são orientações de grupos ou de pessoas que se conhecem. É qualquer informação ou auxílio material vindo de pessoas ou grupos delas que resultam em comportamentos positivos tanto para quem recebe como para quem oferece o apoio, ou seja, é um processo recíproco. As redes de suporte social são formadas por pessoas que mantêm entre si laços típicos das relações sociais, especialmente entre os membros da família, contribuindo para o bem-estar das pessoas e fortalecendo as estratégias para enfrentar a situação do adoecimento (CAMARGO, 2010).

É chamado de informal o apoio que vem da família, amigos, vizinhos, grupos comunitários que podem auxiliar nas atividades de higiene, alimentação, mobilização, na parte financeira e nas tarefas externas (NARDI \& OLIVEIRA, 2008). 
Hegemonia - Revista Eletrônica do Centro Universitário Euro-Americano

ISSN: 1809-1261

UNIEURO, Brasília, número 30, Julho-Dezembro de 2020, pp. 2-27.

O apoio formal vem das relações profissionais: equipes da Saúde da Família, fonoaudióloga, assistente social, físioterapeuta, psicóloga, serviços de vacinas. No Brasil, as estruturas de suporte social não constituem uma rede de apoio organizada, há reduzidas políticas públicas para dar suporte às famílias cuidadoras (NARDI \& OLIVEIRA, 2008).

As casas de repouso, hospitais e consultórios médicos também fazem parte do apoio formal. Importantes também são os investimentos em Programas de Internação Domiciliar (Lei 10.424/2002), que tratam de estratégias para reverter a atenção centralizada em hospitais. Essa lei é uma conquista capaz de proporcionar a prestação de cuidados com a saúde com mais conforto às pessoas clinicamente estáveis e que podem ser tratadas em sua residência. O objetivo da lei é humanizar os atendimentos, reduzir a hospitalização desnecessária, as taxas de reinternação e as infecções hospitalares (BRASIL, 2002).

Pesquisa realizada em São Paulo verificou mudanças positivas no estado emocional do cuidador após treinamento e acompanhamento da equipe de saúde. Esses resultados evidenciam que a saúde mental dos cuidadores pode ser preservada em decorrência do apoio formal. Aqueles idosos que relataram maior satisfação com o apoio recebido sentem menos sobrecarga e menos depressão em comparação aos cuidadores com poucos laços sociais (CAMARGO, 2010). Cuidado então, como altamente representativo no que diz respeito a qualidade de vida dos idosos e, consequentemente, a uma preservação de sua autoimagem e percepção da estima grupal.

2.2 Sobrecarga, saúde e autocuidado do cuidador idoso

A falta de preparo do cuidador idoso para cuidar de outro idoso gera angústia e estresse. Ele não sabe lidar com a doença do outro. Os problemas físicos, psíquicos e sociais decorrentes do ato de cuidar são descritos como burden (do cuidador familiar) ou burnout (do cuidador profissional). Burden é traduzido para o português como sobrecarga para descrever os aspectos do cuidar que alteram negativamente a vida do cuidador quanto ao excesso de preocupações, de culpa e pela ausência de interação com amigos e familiares (CAMARGO, 2010). 
Hegemonia - Revista Eletrônica do Centro Universitário Euro-Americano

ISSN: 1809-1261

UNIEURO, Brasília, número 30, Julho-Dezembro de 2020, pp. 2-27.

\begin{abstract}
Sobrecarga é definido como o estado psicológico que resulta combinação de trabalho físico, tensão emocional, restrição social e dificuldades financeiras, provenientes da atividade de cuidar, consequências essas provenientes de práticas variadas e de demandas emocionais do cuidado (CAMARGO, 2010, p. 239).
\end{abstract}

Essa sobrecarga refere-se às dificuldades do dia a dia: problemas com sua própria saúde (fadiga constante, insônia, dores musculares, cefaleia, depressão, agressividade, dificuldades financeiras, mudanças na rotina, ausência de sociabilidade) e também como o cuidador vê o efeito das dificuldades na sua própria vida (CAMARGO, 2010).

O cuidado é uma representação de preocupações, responsabilidades e envolvimento. No caso dos idosos, espera-se que haja alguém capaz de ajudar naquilo que eles não podem realizar sozinhos. É comprovado que quanto menor o nível de suporte social maior é a sobrecarga do cuidador (GVOZD \& DELLAROZA, 2012).

Segundo Born (2008), o autocuidado não é importante só para o cuidador, mas também para a qualidade dos cuidados com o idoso enfermo. Cuidar de um familiar supõe um excesso de trabalho sem um descanso diário suficiente, sem tempo para fazer o que lhe dá prazer, não visita os amigos, não sai de casa.

\title{
3 DISCUSSÃO DOS RESULTADOS
}

As filhas idosas despontaram como as principais cuidadoras $(50 \%)$, reafirmando o fato de que o cuidado é assumido por respeito, senso de dever e de gratidão, conforme fora afirmado por Neri (2009) e vários outros autores.

$\mathrm{Na}$ análise do perfil dos entrevistados quanto ao gênero, foram encontrados em sua maioria cuidadores familiares idosos do gênero feminino (83\%). O predomínio de mulheres no exercício do cuidado está ligado ao contexto sociocultural, já que o papel da mulher é o de cuidar, satisfazer as necessidades básicas da família, cuidar do bem-estar de todos e da saúde dos filhos e do marido. Essas tarefas do cuidado são ensinadas às mulheres dentro da própria família (NERI, 2009). 
Hegemonia - Revista Eletrônica do Centro Universitário Euro-Americano

ISSN: 1809-1261

UNIEURO, Brasília, número 30, Julho-Dezembro de 2020, pp. 2-27.

Os cuidadores e os idosos dependentes de cuidados coabitavam no momento do diagnóstico da doença, elemento importante para a escolha do cuidador. Nenhum idoso foi previamente capacitado para ser cuidador do outro idoso.

Quanto às condições socioeconômicas, os cuidadores entrevistados são pessoas de poucos recursos financeiros, moradores da periferia de Brasília.

\section{Entrevista 1 - Rosa}

Rosa, de 61 anos de idade, é cuidadora do pai de 86 anos, portador de câncer em estado terminal. Idosos possuem 11 (onze) vezes mais chances de desenvolver neoplasias do que os adultos mais jovens. Ao envelhecer, o corpo perde progressivamente a capacidade física e metabólica para realizar suas funções adequadamente e conservar-se equilibrado (MARTINELLI, 2017). Foi o que aconteceu com o pai de Rosa:

\footnotetext{
Surgiu um câncer no timo, próximo do coração de meu pai [...]. Ficou internado por 4 meses na cardiologia. Depois, subiu para a oncologia. Quando terminou a quimioterapia [...], em casa, caiu e quebrou o quadril. Foram mais 4 meses de hospital. Voltou para casa sem poder andar, o que aumentou muito o cuidado (ROSA).
}

As quedas no envelhecimento são consequências das alterações do sistema musculoesquelético que acontecem por anormalidades do equilíbrio, fraqueza muscular, consumo de medicamentos, dentre outros. O acidente do pai de Rosa aconteceu no domicílio, o que comprova a necessidade de adaptações simples da moradia do idoso para prevenir fraturas. Os cuidadores de idosos leigos em tratamentos de saúde necessitam, antes da alta hospitalar, de orientações sobre a adaptação do ambiente ao idoso. Durante a hospitalização, o cuidador já pode começar a praticar o cuidado, retornando à casa com independência nessa prática, como esclareceram Monteiro e Faro (2016).

Rosa é a única cuidadora familiar de idoso entrevistada que está incluída no projeto Cuidando do Cuidador. Observa-se nela maior autoestima, segurança nos cuidados prestados com qualidade, bom relacionamento familiar embora tenha assumido o cuidado sozinho, o que confirma o fato de que investir nos cuidados ao cuidador repercute positivamente na sua qualidade de vida e na assistência prestada ao idoso cuidado. 
Hegemonia - Revista Eletrônica do Centro Universitário Euro-Americano

ISSN: 1809-1261

UNIEURO, Brasília, número 30, Julho-Dezembro de 2020, pp. 2-27.

\section{Entrevista 2 - Margarida}

A entrevista ocorreu na cozinha da residência da entrevistada, o que demonstrou o quanto ela tentava mostrar que estava à vontade, enquanto preparava a alimentação e lavava roupa. Junto a ela, cuidadora de 70 anos de idade, o idoso doente: marido de 78 anos portador da Doença de Alzheimer (DA). Os idosos cuidadores, apesar de saberem que o cuidado traz prejuízos à sua saúde, não conseguem reconhecer seus limites, talvez pela falta de conhecimento em relação a essa fase da vida em que eles próprios se encontram (Neri, 2009).

Margarida fez questão de narrar como a doença começou:

Comecei a notar que meu marido estava com dificuldade para lembrar das pessoas que tínhamos visto há poucos dias e que eram importantes para nós. Depois foi deixando de falar sobre os assuntos que a gente sempre conversava, às vezes parecia que ele não me conhecia mais. Começou a criar um mundo só para ele (MARGARIDA).

Esses são sintomas próprios do $1^{\circ}$ estágio da DA. Em princípio, a DA caracteriza-se pela dificuldade em lembrar de algo ou alguém. Como provoca degeneração e morte de células do cérebro, o declínio das aptidões mentais é progressivo.

\section{Entrevista 3 - Gardênia}

Gardênia, de 65 anos de idade, cuida do marido de 74 anos, portador do Mal de Alzheimer, segundo ela merecedor do melhor cuidado pelo homem exemplar que foi. Assim falou Gardênia: "Com toda a dificuldade eu cuido dele o melhor que posso porque tudo que tenho dentro de casa devo a ele. Minhas vinte e quatro horas são dele".

Gardênia apresenta dificuldades de adaptar-se a este novo homem que sequer a reconhece. Segundo ela, é um exercício de paciência: "Tudo passa, mas isso parece não ter fim.” (GARDÊNIA) Conforme Neri (2009), o cuidador familiar cansado, ansioso, prisioneiro de um papel que não optou por executar, tem também a incumbência de dar conforto emocional ao idoso doente. Não é só o idoso dependente que é vulnerável, é toda a família. Com esse entendimento concordam Munhoz, Ravagni e Leite (2008). 
Hegemonia - Revista Eletrônica do Centro Universitário Euro-Americano

ISSN: 1809-1261

UNIEURO, Brasília, número 30, Julho-Dezembro de 2020, pp. 2-27.

\section{Entrevista 4 - Violeta}

Marcou a entrevista na Igreja próxima à sua casa. Aos 63 anos de idade, Violeta cuida de sua mãe de 82 anos portadora da Doença de Alzheimer (DA) que, naquele momento, ficara aos cuidados do marido aposentado e idoso. Parecia muito confiante com os cuidados à sua mãe, pois afirmou que o marido cuida da sogra dependente com carinho, embora ela seja uma pessoa difícil de lidar.

Nos cuidados dos idosos com DA, a pesquisa confirmou o entendimento de Fratezi, Gutierres \& Falcão (2010): os sintomas progressivos e graves causam desgaste no cuidador e em toda a família nos cuidados a esse novo idoso dependente que está "substituindo" a mãe ou ao chefe da família, antes independentes e autônomos. A necessidade de uma rede de apoio no cuidado ao idoso foi uma situação que envolveu todos os cuidadores, tanto na ajuda informal vinda da família, quanto na ajuda formal por parte do Estado, como estudado por Perracine e Neri (2002).

Mesmo assim, Violeta mostrou-se ansiosa e prisioneira de um papel que não escolheu executar: "Ela não vive mais, nem eu. Todo mundo ficou doente aqui em casa. A doença é um castigo [...] Todos me pedem que eu tenha paciência com ela. E quem tem paciência comigo?” (VIOLETA)

\section{Entrevista 5 - Orquídea}

Aos 63 anos de idade, Orquídea cuida sozinha da mãe de 84 anos, portadora do Mal de Alzheimer e diverticulite. Aparentava estar muito cansada, sobrecarregada e disse ter sido diagnosticada com depressão. Emocionada, suas lágrimas todo o tempo mostravam sua emoção. Segundo ela, sua mãe "é igual a um bebê." (ORQUÍDEA)

Sintomas depressivos em idosos cuidadores estão associados à sobrecarga e ao estresse. A depressão é um estado de tristeza ou desânimo, perda de interesse e prazer nas atividades, irritação, dificuldade de concentração e pensamentos recorrentes sobre morte devido aos eventos estressantes cotidianos. As pessoas na faixa etária entre 56 e 64 anos 
Hegemonia - Revista Eletrônica do Centro Universitário Euro-Americano

ISSN: 1809-1261

UNIEURO, Brasília, número 30, Julho-Dezembro de 2020, pp. 2-27.

são os que apresentam índice mais elevado de depressão, sendo que no idoso cuidador está associada à sobrecarga e à depressão do idoso dependente.

\section{Entrevista 6 - Cravo}

Cuida da esposa de 71 anos com sequelas de Acidente Vascular Cerebral (AVC) (há 5 anos), diabetes e hipertensão.

Cravo, aos 78 anos de idade, fica feliz por tratar de uma pessoa querida no momento em que ela precisa, sente-se assumindo um papel que só pode ser exercido por ele. $\mathrm{O}$ fato dele ser casado com a idosa doente é importante na decisão de ser o cuidador familiar. É uma expectativa cultural, é uma obrigação. Sua esposa sofreu AVC hemorrágico, que provoca sequelas físicas e cognitivas. As principais incapacidades relacionadas ao AVC estão relacionadas aos déficits no funcionamento físico, com impacto no desempenho das atividades diárias, tais como banho e higiene, alimentação e deslocamento (SCHEFFER, KLEIN \& ALMEIDA, 2013).

A sobrecarga física e psicológica, o sentimento de impotência diante da doença da esposa e os conflitos familiares influenciam de maneira negativa na vida do cuidador, porém, em certos momentos da entrevista, percebia-se que Cravo aceitava os acontecimentos como desafios e a doença da esposa fez com que ele descobrisse a solidariedade da vizinhança e potencialidades próprias que ele desconhecia, tal como foi explicado por Robbe (2008).

A experiência de cuidar de idoso com sequelas de AVC é frequente nas famílias. $\mathrm{Na}$ maioria das vezes, o cuidador não tem capacitação prévia, nenhuma noção de gerontologia, segue sua intuição apoiada em crenças e experiências anteriores ou baseado em informações de terceiros de sua rede social. As principais dificuldades para o cuidador, nesses casos, são o esforço físico, a desinformação, o medo e o constrangimento ao lidar com o corpo do outro (SCHEFFER, KLEIN \& ALMEIDA, 2013).

Além dos problemas que surgem com a má postura pelo esforço para levantar a idosa, os homens são mais negligentes com a saúde do que as mulheres. As dificuldades maiores que serviram de queixa do Cravo são os cuidados diários com a esposa 
Hegemonia - Revista Eletrônica do Centro Universitário Euro-Americano

ISSN: 1809-1261

UNIEURO, Brasília, número 30, Julho-Dezembro de 2020, pp. 2-27.

dependente. Sente-se incompetente para realizar certos procedimentos e preparar a alimentação: "Eu sei mais ou menos que ela não deve comer doces, nem banana, nem biscoitos." (CRAVO)

Cravo fica feliz por tratar de uma pessoa querida no momento em que ela precisa, sente-se assumindo um papel que só pode ser exercido por ele: "Cuido dela porque se eu estivesse no lugar dela, ela fazia o mesmo. Cuido dela porque ela é a minha mulher. Fico satisfeito porque ela tá vendo que eu é que cuido." (CRAVO)

E imprescindível à existência de uma rede de apoio ao cuidador. Se o idoso dependente não tem irmãos, nunca se casou, então não tem mulher nem filhos, se perder a autonomia, o Estado terá de assumir essa responsabilidade garantindo os direitos fundamentais do idoso e sua proteção, talvez em uma Instituição para Idosos. Ainda que o idoso dependente tenha outros familiares que possam cuidá-lo, outra pessoa idosa se vê sozinha na prestação do cuidado sem ter com quem compartilhar o peso da atividade. Quando o cuidador idoso não tem apoio da família, desencadeiam-se os conflitos familiares. Vê-se que dos seis cuidadores entrevistados, todos se queixaram do distanciamento dos parentes próximos.

$\mathrm{O}$ apoio formal recebido pelos cuidadores idosos entrevistados resume-se em: Programa de Internação Familiar, Projeto Cuidando do Cuidador, vacinas, coleta de material para exames laboratoriais no domicílio, empréstimo de cadeira de rodas, serviço de ambulância.

As dificuldades psicofisiológicas do cuidador idoso detectadas na pesquisa foram: falta de dinheiro, esforço físico excessivo para um cuidador idoso, o não reconhecimento da sobrecarga, falta de reconhecimento e distanciamento dos familiares. Quanto mais o cuidador se envolver sozinho com o cuidado, mais os demais familiares se afastam ou entendem a pouca atenção que dão ao pai como uma colaboração, uma cooperação à distância, mas a cuidadora precisa de uma divisão real de tarefas (SILVA \& DIAS, 2016).

Todos os cuidadores entrevistados, cujos idosos tem DA, enfrentam problemas nas ligações familiares, o que vem ao encontro das percepções de Bagne \& Gasparino 
Hegemonia - Revista Eletrônica do Centro Universitário Euro-Americano

ISSN: 1809-1261

UNIEURO, Brasília, número 30, Julho-Dezembro de 2020, pp. 2-27.

(2014) ao dizerem que cuidadores de idosos com demências precisam de ajudas profissionais de áreas diversas: gerontólogos, psicólogos e juristas.

\section{CONCLUSÃO}

Ao término do trabalho pode-se afirmar seguramente que foi realizada uma investigação preliminar, longe de estar concluída. Resta a convicção de terem sido abertas possibilidades de projetos futuros, quer numa lógica de outras investigações quer no sentido de "abrir portas" para a intervenção noutras dimensões na área deste estudo.

A interpretação das entrevistas dos cuidadores idosos revelou as dificuldades do cotidiano nas ações do cuidado que podem implicar em grave depressão e estresse.

A falta de uma política dinâmica de saúde que oriente como tratar de um idoso dependente e da sua doença; a falta de apoio psicológico de profissionais especializados e não só das redes de solidariedade estabelecidas pelos vizinhos e grupos comunitários são dificultadores das atividades dos cuidadores idosos.

Predominaram nesse estudo as cuidadoras do sexo feminino, esposas e filhas, que moravam na mesma casa do idoso adoentado, e a responsabilidade sempre recai sobre uma só pessoa, corroborando o que se leu na literatura sobre o tema. Mesmo quem não optou por ser o cuidador, desempenha esse papel com resignação, afetividade e responsabilidade

Entende-se ser conveniente que as pesquisas com idosos continuem por meio de ações efetivas para consolidar a dignidade de todos eles, através de uma rede de serviços públicos que atenda seus direitos, especialmente na doença. $\mathrm{O}$ envelhecimento e as fragilidades da velhice precisam ser entendidos como questões intrínsecas à sociedade contemporânea, logo, dizem respeito a todos: família, governo, profissionais da saúde.

Os dados colhidos refletem uma realidade local e não podem ser generalizados, mas contribuem para mostrar que existem idosos cuidando de outros idosos e estão precisando de receber atenção e cuidado. 
Hegemonia - Revista Eletrônica do Centro Universitário Euro-Americano

ISSN: 1809-1261

UNIEURO, Brasília, número 30, Julho-Dezembro de 2020, pp. 2-27.

\section{REFERÊNCIAS}

ABDALA, G. A., et alli. Religiosidade e qualidade de vida relacionada à saúde do idoso. Revista Saúde Pública, v. 49, n. 55, pp. 49-55, 2015.

BAGNE, B., GASPARINO, R. Qualidade de vida do cuidador do portador de Doença de Alzheimer. Revista de Enfermagem da UERJ, v. 22, n. 2, pp. 258-263, 2014.

BALTHES, P. B., SMITH, J. Novas fronteiras para o futuro do envelhecimento. Revista A Terceira Idade, v. 17, n. 36, pp. 7-31, 2006.

BARDIN, L. Análise de conteúdo. São Paulo: Edições 70, 2011.

BARROS, R. Por uma história do velho ou do envelhecimento no Brasil. CESJF Revista, v. 27, n.1, p. 75-92, 2013.

BEAUVOIR, Simone. A velhice. São Paulo: Difusão Europeia do Livro, 1990.

BORN, T. (Org.). Cuidar melhor e evitar a violência: Manual do cuidador da pessoa idosa. Brasília, Secretaria Especial dos Direitos Humanos, 2008.

BRASIL. Lei 10.424, de 15 de abril de 2002. Regulamenta a Assistência Domiciliar no SUS e dá outras providências. Brasília: Presidência da República, 2002.

BRASIL. Lei 10.741, de 01 de outubro de 2003. Estatuto do Idoso. Brasília: Ministério da Saúde, 2011.

BRASIL. Redes de atenção à saúde no SUS. Ministério da Saúde. Disponível em: http://www.saude.mg.gov.br/sus, 2016. Acesso em: 13 abr. 2018.

BRASIL. Portaria $\mathbf{n}^{\mathbf{0}}$ 825, de 25 de abril de 2016. Serviço de Atenção Domiciliar no âmbito do SUS. Ministério da Saúde. Disponível em: http://bvsms.saude.gov.br/bvs/saudelegis/gm/2016/prt0825 4 2016. Acesso em: 07 jul. $2016 \mathrm{a}$.

BUDÓ, M. \& RESTA, D. A cultura e as formas de cuidar em família na visão de pacientes e cuidadores domiciliares. Acta Scientiarum. Health Sciences. Maringá, v. 26, n. 1, pp. 53-60, 2004.

CAMARANO, A. A. Os novos idosos brasileiros. Muito além dos 60? Rio de Janeiro: IPEA, 2004.

CAMARGO, R. C. Implicações na saúde mental de cuidadores de idosos: uma necessidade urgente de apoio formal. Revista Saúde Mental, Álcool e Drogas, v. 6, n. 2, pp. 231-250, 2010. 
Hegemonia - Revista Eletrônica do Centro Universitário Euro-Americano

ISSN: 1809-1261

UNIEURO, Brasília, número 30, Julho-Dezembro de 2020, pp. 2-27.

CARVAlHO, J. A. \& GARCIA, R. A. O envelhecimento da população brasileira. Caderno de Saúde Pública, Rio de Janeiro, v. 19, n. 3, pp. 725-733, 2003.

DOURADO, D. M. et ali. Ansiedade e depressão em cuidador familiar de pessoa com transtorno mental. ECOS | Estudos Contemporâneos da Subjetividade, v. 1, ano 8, pp. 153-167, 2018.

FIOCRUZ. Fundação Oswaldo Cruz. (2014). Saúde do idoso: país começa a ser reconhecido por suas políticas públicas. Disponível em: $<\underline{\mathrm{http}}$ ://portal.fiocruz.br/ptbr/content/saude-do-idoso.html $>$. Acesso em: 13 abr. 2018.

FLORIANI, C. A. \& SCHRAMM, F. R. Cuidador do idoso com câncer avançado. Cadernos de Saúde Pública, v 22, n. 3, 2016.

FONTAINE, R. Psicologia do envelhecimento. São Paulo: Loyola, 2010.

FRATEZI, F., GUTIERREZ, B. \& FALCÃO, D. Doença crônica: o processo de morrer e a morte do idoso na família. In: FALCÃO, D. (Org.). A família e o idoso. Campinas/SP: Papirus, pp. 191-210, 2010.

GASKELL, G. \& BAUER, M. (Orgs.). Pesquisa qualitativa com texto, imagem e som: um manual prático. 9a ed. Petrópolis: Vozes, 2011.

GONÇALVES, L. T. et alli. Convívio e cuidado familiar na quarta idade: qualidade de vida de idosos e seus cuidadores. Revista Brasileira de Geriatria e Gerontologia, v. 16, n. 2, pp. 315-325, 2013.

Gratão, A. C. et ali. Dependência funcional de idosos e a sobrecarga do cuidador. Revista de Enfermagem USP, v. 47, n. 1, pp. 137-144, 2013.

GVOZD, R. \& DELLAROZA, M. S. Velhice e a relação com idosos. Revista Brasileira de Geriatria e Gerontologia, v. 15, n. 2, pp. 295-304, 2012.

IBGE. Instituto Brasileiro de Geografia e Estatística. Estimativas da população 2015. Disponível em: http://www.ibge.gov.br/Estimativas_de_populacao/Estimativas_2015>. Acesso em: 13 abr. 2018.

IBGE. Instituto Brasileiro de Geografia e Estatística. População do Brasil com 25 anos ou mais. (2016). Disponível em: http://agenciadenoticias.ibge.gov.br/agencianoticias/pnad-continua-2016/. Acesso em: 01 jul. 2018.

MARTINELLi, Juliana. Por que a idade é fator de risco para o câncer? Disponível em: http://idosos. com.br/incidencia-de-cancer-em-idosos, 2017. Acesso em: 06 jul. 2018. 
Hegemonia - Revista Eletrônica do Centro Universitário Euro-Americano

ISSN: 1809-1261

UNIEURO, Brasília, número 30, Julho-Dezembro de 2020, pp. 2-27.

MARTINEZ, A., CONSTANTINO \& B., MESSINA, C. Percepções sobre o cuidado com idosos portadores de Alzheimer: contribuições a partir dos discursos da equipe de enfermagem. Revista Faculdade de Ciências Médicas de Sorocaba, v. 16, n. 2, pp. 7679, 2014.

MONTEIRO, C. R. \& FARO, A. C. O cuidador do idoso e sua compreensão sobre a percepção e o tratamento das fraturas de fêmur. Estudos Interdisciplinares Envelhecimento. V. 10, pp. 105-121, 2016.

MOREIRA, V. \& NOGUEIRA, F. Do indesejável ao inevitável: a experiência vivida do estigma de envelhecer na contemporaneidade. Revista USP, v. 19, n. 1, pp. 59-79, 2008.

MUNHOZ, C., RAVAGNI, L. \& LEITE. Como a família ajuda ou dificulta o cuidado para a pessoa idosa. In: Born, T. (Org.). Cuidar melhor e evitar a violência. Brasília: Secretaria Especial dos Direitos Humanos, 2008.

NARDI, E. F. \& OLIVEIRA, M. L. Conhecendo o apoio social ao cuidador familiar do idoso. Revista Gaúcha de Enfermagem, v. 29, n. 1, pp. 47-53, 2008.

NERI, A.A. O envelhecimento no universo do trabalho: desafios e oportunidades depois dos 50 anos. In: Barros, J.C. (Org.) Empreendedorismo, trabalho e qualidade de vida na terceira idade. São Paulo: Edicon, 2009.

NETTO, M. P., LUDERS, S. L. \& KLEIN, E.L. Demência: impacto sobre cuidador, família e sociedade. In: NETTO, M. T. Tratado de gerontologia. $2^{a}$ ed. São Paulo: Atheneu, pp. 339-368, 2007.

OTTONI, M. A. A trajetória das políticas públicas de amparo ao idoso no Brasil. Dissertação de Mestrado em Desenvolvimento Social. Universidade Estadual de Montes Claros. Montes Claros/MG, 2011.

PASCHOAL, S. D. Diminuição da capacidade funcional, fragilização e dependência. In: BORN, T. (Org.). Cuidar melhor e evitar a violência: Manual do cuidador da pessoa idosa. Brasília: Secretaria Especial dos Direitos Humanos, pp. 113-120, 2008.

PERRACINE, M. B. \& NERI, A. L. Tarefas de cuidar: com a palavra, mulheres cuidadoras de idosos de alta dependência. In: Neri, A. L. (ed.) Cuidar de idosos no contexto da família. Campinas: Alínea, pp. 137-166, 2012.

PEREIRA, L. L. \& DIAS, A. O familiar cuidador do paciente terminal. Revista Psicologia em Estudo, v. 38, n. 1, pp. 55-65, 2007.

PESSOA, A, I. O envelhecimento na agenda da política social brasileira: avanços e limitações. Tese de Doutorado em Política Social. UNB: Brasília, 2008. 
Hegemonia - Revista Eletrônica do Centro Universitário Euro-Americano

ISSN: 1809-1261

UNIEURO, Brasília, número 30, Julho-Dezembro de 2020, pp. 2-27.

RAVAGNi, L. O cuidador da pessoa idosa: formação e responsabilidades. In: BORN, T. (Org.). Cuidar melhor e evitar a violência: Manual do cuidador da pessoa idosa. Brasília: Secretaria Especial dos Direitos Humanos, pp. 53-63, 2008.

RIBEIRO, P. C, NERI, A. L., CUPERTINO \& A. P., YASSUDA, M. S. Variabilidade no envelhecimento ativo segundo gênero, idade e saúde. Revista Psicologia em Estudo, v. 14, n. 8, pp. 501-509, 2009.

ROBBE, J. O cuidador principal e sua relação com os demais cuidadores. In: BORN, T. (Org.) Cuidar melhor e evitar a violência: Manual do cuidador da pessoa idosa. Brasília: Secretaria Especial dos Direitos Humanos, pp. 64-69, 2008.

ROZENDO, A. \& JUSTO, J. Velhice e terceira idade: tempo, espaço e subjetividade. Revista Kairós Gerontologia, v. 14, n. 2, pp. 143-159, 2011.

SCHEFFER, M., KLEIN, L. A. \& ALMEIDA, R. M. Reabilitação neuropsicológica em pacientes com lesão vascular cerebral. Avances em Psicologia Latinoamericana, v. 31, n. 1, pp. 46-61, 2013.

SEIMA, M. D.; LENARDT, M. H. \& CALDAS, C. P.. Relação no cuidado entre o cuidador familiar e o idoso com Alzheimer. Revista Brasileira de Enfermagem vol.67, n.2, pp.233-240. ISSN 0034-7167, 2014. https://doi.org/10.5935/0034-7167.20140031. Acesso em: 06 jul. 2018.

SILVA, C. F. S. \& DIAS, C. M. de S. B. Violência Contra Idosos na Família: Motivações, Sentimentos e Necessidades do Agressor. Revista Psicologia: ciência e profissão. vol.36, n.3, pp.637-652. ISSN 1982-3703, 2016. https://doi.org/10.1590/1982-3703001462014. Acesso em: 22 jul. 2019.

Recebido em: 08.04.2020

Avaliado em: 20.06.2020

Aprovado em: 23.07.2020 